\title{
Intratracheally administered titanium dioxide or carbon black nanoparticles do not aggravate elastase-induced pulmonary emphysema in rats
}

\author{
Agnès Roulet ${ }^{1,2 \dagger}$, Lucie Armand ${ }^{1,2+}$, Maylis Dagouassat ${ }^{1,2}$, Françoise Rogerieux ${ }^{3}$, Angélique Simon-Deckers ${ }^{1,2}$, \\ Esther Belade ${ }^{1,2}$, Jeanne Tran Van Nhieu ${ }^{2,4}$, Sophie Lanone ${ }^{1,2,5}$, Jean-Claude Pairon ${ }^{1,2,5}$, Ghislaine Lacroix ${ }^{3}$ \\ and Jorge Boczkowski ${ }^{1,2,5,6^{*}}$
}

\begin{abstract}
Background: Titanium dioxide $\left(\mathrm{TiO}_{2}\right)$ and carbon black (CB) nanoparticles (NPs) have biological effects that could aggravate pulmonary emphysema. The aim of this study was to evaluate whether pulmonary administration of $\mathrm{TiO}_{2}$ or CB NPs in rats could induce and/or aggravate elastase-induced emphysema, and to investigate the underlying molecular mechanisms.
\end{abstract}

Methods: On day 1, Sprague-Dawley rats were intratracheally instilled with $25 \mathrm{U} \mathrm{kg}^{-1}$ pancreatic porcine elastase or saline. On day 7, they received an intratracheal instillation of $\mathrm{TiO}_{2}$ or $\mathrm{CB}$ (at 100 and $500 \mu \mathrm{g}$ ) dispersed in bovine serum albumin or bovine serum albumin alone. Animals were sacrificed at days 8 or 21, and bronchoalveolar lavage (BAL) cellularity, histological analysis of inflammation and emphysema, and lung mRNA expression of heme oxygenase-1 (HO-1), interleukin-1 $\beta$ (IL-1 $\beta$ ), macrophage inflammatory protein-2, monocyte chemotactic protein-1, and matrix metalloprotease (MMP)-1, and -12 were measured. In addition, pulmonary MMP-12 expression was also analyzed at the protein level by immunohistochemistry.

Results: $\mathrm{TiO}_{2} \mathrm{NPs}$ per se did not modify the parameters investigated, but CB NPs increased perivascular/ peribronchial infiltration, and macrophage MMP-12 expression, without inducing emphysema. Elastase administration increased BAL cellularity, histological inflammation, HO-1, IL-1 $\beta$ and macrophage MMP-12 expression and induced emphysema. Exposure to $\mathrm{TiO}_{2} \mathrm{NPs}$ did not modify pulmonary responses to elastase, but exposure to CB NPs aggravated elastase-induced histological inflammation without aggravating emphysema.

Conclusions: $\mathrm{TiO}_{2}$ and CB NPs did not aggravate elastase-induced emphysema. However, CB NPs induced histological inflammation and MMP-12 mRNA and protein expression in macrophages.

Keywords: COPD, Occupational medicine, Particles, Toxicity

\section{Background}

Pulmonary emphysema is a chronic degenerative lung disease characterized by an imbalance in alveolar destruction and repair that results in progressive destruction of pulmonary alveoli and chronic respiratory failure [1]. Pulmonary emphysema is one of the components of chronic obstructive pulmonary disease (COPD), a frequent

\footnotetext{
* Correspondence: jorge.boczkowski@inserm.fr

'Equal contributors

1 Inserm U955, Equipe 4, Créteil 94000, France

${ }^{2}$ Université Paris Est, Faculté de Médecine, Créteil 94000, France

Full list of author information is available at the end of the article
}

condition with a worldwide prevalence of more than $10 \%$ in men older than 40 years. The prevalence and mortality of COPD are predicted to further increase in the next decades [2]. Different processes are involved in alveolar destruction in emphysema, particularly excess of protease expression and activity in the lung. In addition to neutrophil elastase, macrophage matrix metalloproteinase (MMP)-1 and -12 have a critical role in pulmonary emphysema (see reference [3] for review).

Nanotechnology is a continually developing field. Reducing a particle's size to the nanometric dimension can greatly modify its properties for applications in

\section{() Biomed Central}


numerous fields such as electronics, materials or health. However, concerns have arisen about the possible effects of these manufactured nanoparticles (NPs) on the health of users and/or workers manipulating them [4]. Indeed, the adverse health effects and toxicity of NPs are being increasingly evaluated (see for example reference [5]).

Titanium dioxide $\left(\mathrm{TiO}_{2}\right)$ is one of the most abundantly produced NPs [6]. Because of its optical, photocatalytic and self-cleaning properties, it is widely used in paints, pigments, and cosmetics. Nevertheless, exposure to $\mathrm{TiO}_{2}$ NPs has various biological effects [7]. Respiratory exposure to $\mathrm{TiO}_{2}$ NPs in animals was found associated with pulmonary inflammation $[8,9]$, parenchymal remodeling [10], including emphysema [11], and cancer [12]. $\mathrm{TiO}_{2}$ NPs exposure has been linked to an increase in MMP expression: MMP-12 in murine macrophages [13] and MMP-7, -9 and -10 in keratinocytes [14]. Moreover, $\mathrm{TiO}_{2}$ NPs induced the expression of interleukin-1 $\beta$ (IL-1 $\beta$ ) [9], a strong inducer of MMP-1 [15]. Therefore, we hypothesized that exposure to $\mathrm{TiO}_{2}$ NPs could lead to and/or aggravate pre-existing pulmonary emphysema, given the roles of MMP-1 and MMP-12 in the pathophysiology of the disease [1]. The potential aggravation of pre-existing emphysema by $\mathrm{TiO}_{2} \mathrm{NPs}$ is important because of the frequency of COPD and the possibility of patients with COPD having been exposed to $\mathrm{TiO}_{2} \mathrm{NPs}$.

Carbon black (CB) NPs are also abundantly produced [6]. Exposure to CB NPs can induce cell apoptosis [16], inflammation [17], or aggravate already existing pathologic conditions such as elastase-induced lung injury [18]. However, the comparative effects of $\mathrm{CB}$ and $\mathrm{TiO}_{2}$ NPs on emphysema induction or aggravation have not been examined yet. This is an important point because the effects of NPs depend in part on their chemical nature, and thus we can expect differences in emphysema generation and/or aggravation related to the chemical nature of the considered NP.

Therefore, we aimed to assess whether pulmonary administration of $\mathrm{TiO}_{2}$ or CB NPs in rats could induce and/or aggravate emphysema and to investigate the molecular mechanisms involved. We used a wellestablished elastase-induced pulmonary emphysema rat model, which reproduces key phenomena occurring in alveolar walls of patients with emphysema [19-21]. NPs were administered 7 days after elastase instillation, to assess the effects on the development of already constituted but still progressing emphysema [21]. We examined animals at 2 time-points and exposed them to 2 doses of $\mathrm{TiO}_{2}$ or CB NPs. We also characterized the physicochemical properties of NPs in terms of size, morphologic features, surface area, degree of dispersion and endotoxin content, as factors able to influence their biological properties [5,22].

\section{Methods}

\section{Chemicals}

Anatase $\mathrm{TiO}_{2}$ NPs (reference 637264) were purchased from Sigma Aldrich (St Louis, MO, USA). CB NPs (reference Carbon Black FW 2) were purchased from Degussa (Dusseldorf, Germany). In order to disperse NPs using a biological agent, $\mathrm{TiO}_{2}$ and CB NPs were suspended in $0.5 \mathrm{mg} / \mathrm{ml}$ bovine serum albumin (BSA, Sigma Aldrich, St Louis, MO, USA) as described previously [23].

\section{Characterization of NPs}

Specific surface area was measured using Brunauer Emmett Teller (BET) adsorption isotherms of nitrogen at $77 \mathrm{~K}$. Particle Size Distribution (PSD) function and zeta potential were determined in saline $+0.5 \mathrm{mg} / \mathrm{ml}$ BSA using a Zetasizer Nano S (Malvern Instruments Ltd, Worcestershire, UK). Transmission electronic microscopy (TEM) was performed in NPs suspensions filtered and dried overnight on 200-mesh copper grids. Representative images of the samples were taken using a JEOL 1200 EXII transmission electron microscope (OXFORD LINK ISIS 300) and analyzed using an image analyzer (SAISAM Software, Microvision). NPs endotoxin content was examined using the Limulus Amebocyte Lysate (LAL) kit QCL-1000 (Lonza, Basel, Switzerland) according to the manufacturer's instructions.

\section{Animals}

240 male Sprague-Dawley rats aged 6 to 8 weeks were purchased from Janvier (Le Genest Saint Isle, France). The rats were kept in a conventional animal facility and housed in positive-pressure air-conditioned units $\left(22^{\circ} \mathrm{C}\right.$, $60 \%$ relative humidity) on a $12 \mathrm{~h}: 12 \mathrm{~h}$ light/dark cycle. They had ad libitum access to food and water. The experimental protocol has been approved by the ethical committee for animal research of the INERIS ("Institut National de l'Environnement Industriel et des Risques", French National Institute of Industrial Environment and Risks).

\section{Intratracheal instillation studies}

All animals were anaesthetized by intramuscular injection of a mixture of ketamine (1.6 mg, Merial, Lyon, France) and xylazine (300 $\mu$ g, Bayer, Puteaux, France). The trachea was surgically exposed, and sterile saline solution or $25 \mathrm{U} \mathrm{kg}^{-1}$ porcine pancreatic elastase (Elastin Products, Owensville, MO) diluted in sterile saline solution was instilled, in a volume of $150 \mu \mathrm{l}$. Seven days after elastase or saline instillation (D7), rats underwent intratracheal instillation with BSA $(0.5 \mathrm{mg} / \mathrm{ml})$ or $\mathrm{TiO}_{2}$ or CB NPs $(100$ or $500 \mu \mathrm{g} / \mathrm{rat})$. Half of the rats were sacrificed the day after NPs instillation (day 8 [D8] after elastase), and the other half 14 days after NPs instillation (day 21 
[D21] after elastase). Therefore, 6 groups of animals ( $n=10$ in each one) were constituted per sacrifice time (D8 and D21, respectively) and per dose of NPs (100 $\mu \mathrm{g}$ and $500 \mu \mathrm{g}$, respectively): saline + BSA (S-BSA), saline + $\mathrm{TiO}_{2}\left(\mathrm{~S}-\mathrm{TiO}_{2}\right)$, saline $+\mathrm{CB}(\mathrm{S}-\mathrm{CB})$, elastase $+\mathrm{SA}(\mathrm{E}-\mathrm{BSA})$, elastase $+\mathrm{TiO}_{2}\left(\mathrm{E}-\mathrm{TiO}_{2}\right)$, and elastase $+\mathrm{CB}(\mathrm{E}-\mathrm{CB})$.

For each experimental condition, 2 groups (group $\mathrm{A}$ and group B) of rats were used, with 6 animals in group A and 4 in group B. Bronchoalveolar lavage (BAL) and Real-Time quantitative PCR (RT-qPCR) of the total lung were performed on rats included in group A. Histopathology and immunohistochemistry were performed in the lungs of rats included in group B. These lungs were fixed by airway instillation with $4 \%$ phosphate buffered paraformaldehyde at a pressure of $20 \mathrm{~cm}$ fluid column for $24 \mathrm{~h}$, before being embedded in paraffin. Great-axis sagittal sections $(5 \mu \mathrm{m})$ were performed in a systematic manner on the same part of the lung. Some sections were stained with hematoxylin and eosin (H\&E) for histological studies; others were kept unstained for immunohistochemical analysis.

\section{Broncho alveolar lavage cellularity}

BAL cellularity was analyzed in anesthetized animals as previously described [24].

\section{Histopathological analysis}

We quantified histological markers of inflammation and emphysema by optical microscopy (Zeiss Axiophot, Carl Zeiss, Oberkochen, Germany). The inflammatory abnormalities studied were the following: alveolar inflammation, perivascular oedema and perivascular/peribronchial infiltration as described previously [25]. Analysis and quantification of the histopathological alterations were performed by 2 independent investigators, including an unrelated expert pathologist who was blinded from the experimental design and the treatments the animals received. From every animal, four to five sections were taken from different depths to give a representative appreciation of the whole lung. All histological alterations of the same type present on each section were photographed, and surrounded using the Zeiss Axiovision 40 software (Carl Zeiss), which gave the corresponding area for each alteration. In each section, a global alteration score of each inflammatory abnormality was calculated as the sum of the areas obtained. Median areas were determined from the different sections of the individual animals, and area values of the different experimental groups were calculated from the individual values.

Emphysema was quantified as described previously $[24,26]$. Briefly, the lungs were fixed with $2.5 \%$ glutaraldehyde at a transpleural pressure of $25 \mathrm{cmH}_{2} \mathrm{O}$ for $3 \mathrm{~h}$ and held in $4 \%$ paraformaldehyde (Sigma). Great-axis sagittal sections $(5 \mu \mathrm{m})$ of the left lung were cut in a systematic fashion and were stained with hematoxylin and eosin. Three black-and-white digital photomicrographs were acquired from the cranial, medial, and caudal regions of each slide at X40 magnification, excluding areas where large bronchi or vessels predominated, resulting in a total of 9 images per lung. Emphysema was then quantified by measurement of the mean chord length of alveoli [27,28] with Analysis software (Soft Imaging System, Münster, Germany) at a $5-\mu \mathrm{m}$ interval. The analysis was performed in duplicate by two blinded observers (AR and LA). The mean chord length of alveoli was obtained by averaging those measurements.

\section{RT-qPCR}

RT-qPCR in lung homogenates was performed to examine the mRNA expression of anti-oxidant, inflammatory and proteases genes as previously described [24]. Genes analyzed were heme oxygenase $1(\mathrm{HO}-1)$, interleukin $1 \beta$ (IL-1 $\beta)$, macrophage inflammatory protein 2 (MIP-2), monocyte chemotactic protein 1 (MCP-1), MMP-1 and MMP-12. The primer sequences are given in Table 1. Gene expression was normalized to that of hypoxanthine phosphoribosyltransferase (HPRT) as a housekeeping gene.

\section{Immnunohistochemistry}

Immunohistochemical staining was performed to detect the protein expression of MMP-12 (anti-MMP-12 antibody, Santa Cruz Biotechnology, Santa Cruz, CA; 1:100 dilution) and the macrophage marker CD68 (anti-CD68 antibody, Abcam, Cambridge, UK; dilution 1:200). Quantification was performed using ImageJ software [29]. Results were expressed as the percentage of stained cells versus total cells.

Table 1 Primers used for real-time PCR

\begin{tabular}{|c|c|c|c|}
\hline Name & $\begin{array}{c}\text { Genbank } \\
\text { Accession } \\
\text { Number }\end{array}$ & Sequences $\left(5^{\prime}->3^{\prime}\right)$ & $\begin{array}{l}\text { Product } \\
\text { size (bp) }\end{array}$ \\
\hline $\mathrm{HO}-1$ & NM_012580.2 & $\begin{array}{c}\text { TGCTGACAGAGGAACACAAAGA } \\
\text { CGGTCGCCAACAGGAAACT }\end{array}$ & 186 \\
\hline$I L-1 \beta$ & NM_031512.2 & $\begin{array}{l}\text { CTGTGACTCGTGGGATGATG } \\
\text { GGGATIITGTCGTTGCTTGT }\end{array}$ & 210 \\
\hline MCP-1 & NM_031530 & $\begin{array}{l}\text { CCAGAAACCAGCCAACTCTCA } \\
\text { TGTGAACAACAGGCCCAGAAG }\end{array}$ & 90 \\
\hline MIP-2 & NM_053647.1 & $\begin{array}{c}\text { AGGATCGTCCAAAAGATACTGAACA } \\
\text { TTGATTCTGCCCGTTGAGGTA }\end{array}$ & 90 \\
\hline MMP-1 & NM_001134530.1 & $\begin{array}{l}\text { GCCAACAGGTGCAACAACAC } \\
\text { GCATCAAGTITACCTGGCAGATT }\end{array}$ & 186 \\
\hline MMP-12 & NM_053963.2 & $\begin{array}{l}\text { CCCCAACACATTCGTCTCTCT } \\
\text { GGATITGTCAAGGATGGGTT }\end{array}$ & 90 \\
\hline HPRT & NM_012583.2 & $\begin{array}{l}\text { TTGGAAAGGGTGTITATTCCTCAT } \\
\text { ATCCAGCAGGTCAGCAAAGAA }\end{array}$ & 261 \\
\hline
\end{tabular}

Abbreviations: $H O-1$ heme oxygenase- $1, I L-1 \beta$ interleukin- $1 \beta, M C P-1$ macrophage inflammatory protein-2, MIP-2 monocyte chemotactic protein-1, MMP-1 matrix metalloprotease-1, MMP-12 matrix metalloprotease-12, HPRT hypoxanthine phosphoribosyltransferase. 


\section{Statistics}

Data were expressed as median and interquartile range (IQR; $25^{\text {th }}$ and $75^{\text {th }}$ percentiles). Analysis was performed using GraphPad Prism 4.0 software (La Jolla, CA, USA). Comparisons between multiple groups were performed using Kruskall-Wallis non-parametric ANOVA followed by Mann-Whitney $U$ test when a difference was detected. All comparisons were realized with correction for multiple comparisons. $p<0.05$ was considered statistically significant.

\section{Results}

\section{Characterization of NPs}

The detailed physicochemical characterization of NPs (surface area, primary particle size, zeta potential and hydrodynamic diameter) is given in Table 2. CB NPs had a higher specific surface area than $\mathrm{TiO}_{2}$ NPs $(p<0.05)$. The primary diameter of $\mathrm{CB}$ and $\mathrm{TiO}_{2}$ NPs was not statistically different. The zeta potential for $\mathrm{CB}$ and $\mathrm{TiO}_{2}$ NPs, used to indicate suspension stability, was about $|20| \mathrm{mV}$, a commonly used limit above which the suspension is aggregated [30]. Indeed, PSD studies showed aggregation for both NPs, with a higher average hydrodynamic diameter of $\mathrm{CB}$ as compared to $\mathrm{TiO}_{2}$ NPs. However, as for the primary diameter, this difference was not statistically significant.

No endotoxin was detected whatever NP (data not shown).

\section{BAL cellularity}

At D8 and D21, with saline treatment, NPs instillation (at both 100 and $500 \mu \mathrm{g} / \mathrm{rat}$ ) did not modify BAL cellularity (Figure 1). By contrast, in presence or absence of NPs, elastase induced a significant increase in total BAL cellularity as compared to saline treatment $(p<0.05$, Figure 1). Alveolar macrophages represented more than $80 \%$ of total cells in BAL, with no significant difference between groups (Figure 2).

\section{Emphysema quantification}

Emphysema was quantified at D21 as described previously [24,26]. NPs did not induce emphysema per se (Figure 3). As expected, mean airspace chord length was greater with elastase than saline treatment $(p<0.05$,
Figure $3 \mathrm{~A}, \mathrm{~B})$, in absence or presence of whatever dose of NPs.

Considering that the effects of NPs on BAL cellularity and emphysema were similar when the animals were exposed to 100 or $500 \mu \mathrm{g}$ NPs, we used $500 \mu \mathrm{g}$ NPs for the remaining studies.

\section{Histological analysis of inflammation}

At D8 and D21, rats receiving saline or elastase showed no alveolar inflammation nor perivascular oedema in absence or presence of NPs (Figure 4A-4D).

At D8, with saline treatment, perivascular infiltration was greater in rats exposed to $\mathrm{CB}$ but not $\mathrm{TiO}_{2} \mathrm{NPs}$ than BSA-treated animals $(p<0.05$, Figure 4E). Elastase treatment resulted in a significant increase in perivascular infiltration $(p<0.05$, Figure $4 \mathrm{E})$. Moreover, exposure of elastase-treated rats to $\mathrm{CB}$ slightly but significantly increased this phenomenon. The infiltrates were mainly composed of lymphocytes, with also neutrophils and macrophages (Figure 4G). Some infiltrates were also located peribronchially. A similar pattern was observed at D21 (Figure 4F).

\section{Gene expression quantification}

At D8, no induction of HO-1, IL-1 $\beta$, MIP-2, MCP-1, MMP-1 or MMP-12 was observed after NP exposure alone, elastase instillation alone or elastase followed by NP exposure (data not shown).

At D21, with saline treatment, the mRNA levels of HO-1 and MMP-12 were increased in rats exposed to $\mathrm{CB}$ but not $\mathrm{TiO}_{2}$ NPs $(p<0.05$; Figure $5 \mathrm{~A}, \mathrm{~F})$. With elastase treatment, the mRNA levels of HO-1, IL- $1 \beta$ and MMP-12 were higher than that with saline treatment (Figure 5A, B and F); a similar pattern was observed in rats instilled with $\mathrm{CB}$ NPs. With elastase treatment, the mRNA level of MMP-12 was higher in rats with $\mathrm{TiO}_{2}$ exposure than BSA exposure (Figure 5F).

\section{MMP-12 and CD68 immunohistochemical analysis}

To verify whether the increase in MMP-12 mRNA level was also observed at the protein level, we analyzed the protein expression of MMP-12 at D21 by immunohistochemical staining. With saline treatment, staining for MMP-12 protein was greater with CB NPs than BSA exposure $(p<0.05$, Figure $6 \mathrm{~A}, \mathrm{~B})$. Moreover, staining

Table 2 Nanoparticles characterization

\begin{tabular}{|c|c|c|c|c|c|}
\hline Nanoparticle & Crystal phase & $\begin{array}{l}\text { Surface area } \\
\left(\mathrm{m}^{2} / \mathrm{g}\right)\end{array}$ & $\begin{array}{l}\text { Average size } \\
(\mathrm{nm})(\mathrm{a})\end{array}$ & $\begin{array}{l}\text { Zeta potential } \\
(\mathrm{mV})\end{array}$ & $\begin{array}{l}\text { Hydrodynamic } \\
\text { diameter }(\mathrm{nm})\end{array}$ \\
\hline$\overline{C B}$ & Amorphous & $373 \pm 18 *$ & $23 \pm 6$ & -21.4 & $613 \pm 145$ \\
\hline $\mathrm{TiO}_{2}$ & Anatase & $141 \pm 6$ & $12 \pm 2$ & -16.9 & $451 \pm 80$ \\
\hline
\end{tabular}

*: $p<0.05$ vs $\mathrm{TiO}_{2}$. 

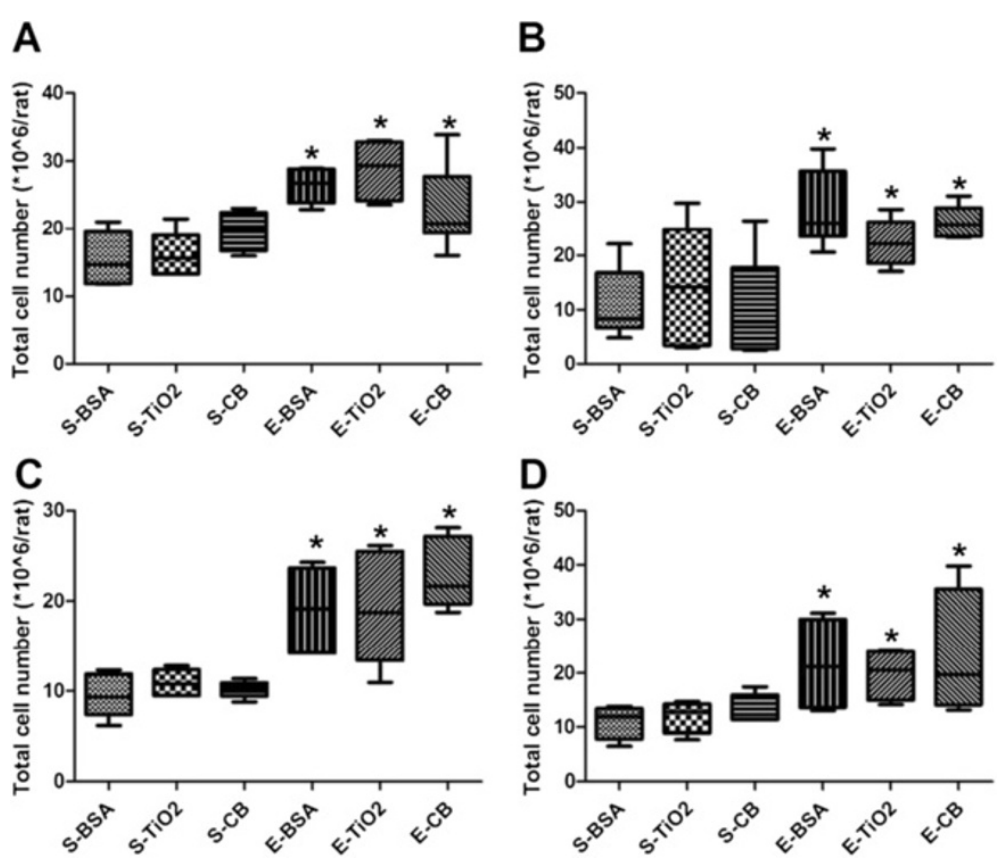

Figure 1 Total cell number in BAL. Quantification of BAL total cell number at D8 (A, C) and D21 (B, D) post elastase treatment, in presence of $100 \mu \mathrm{g}(\mathbf{A}, \mathbf{B})$ or $500 \mu \mathrm{g} \mathrm{NPs}(\mathbf{C}, \mathbf{D})$. S, saline; E, elastase; BSA, bovine serum albumin. CB, carbon black. TiO ${ }_{2}$, titanium dioxide. *: $p<0.05$ vs S-BSA. $\mathrm{n}=6$. Box plots show median and interquartile range $\left(25^{\text {th }}\right.$ and $75^{\text {th }}$ percentiles).

was greater with elastase than saline treatment, regardless of NP exposure.

Because MMP-12-positive cells showed morphologic features of macrophages, we verified this by performing CD68 immunostaining in a serial slide compared to the one in which MMP-12 was detected. Figure 6C shows results for CD68 staining similar to that for MMP-12 staining. Besides, most cells expressing MMP-12 also expressed CD68, which strongly suggests that cells expressing MMP-12 were macrophages. Stained cells
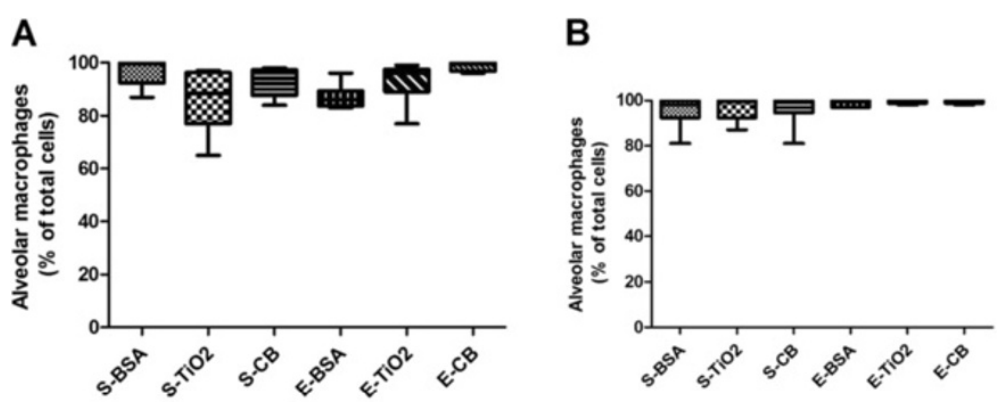

C

D
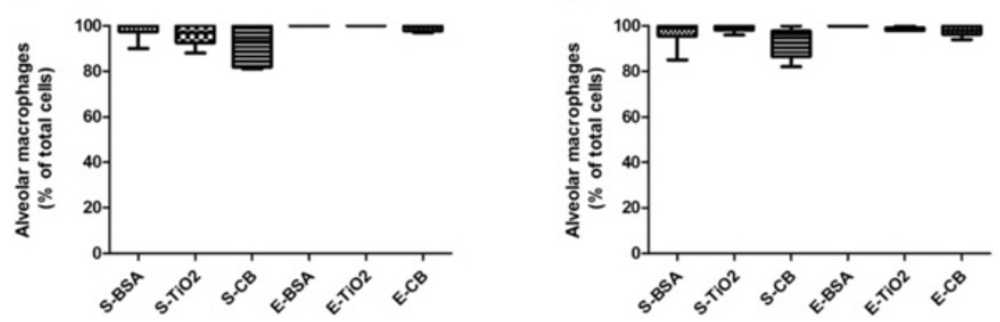

Figure 2 Proportion of alveolar macrophages in BAL. Quantification of the differential cell count in BAL at D8 (A, C) and D21 (B, D) post elastase treatment, in presence of $100 \mu \mathrm{g}(\mathbf{A}, \mathbf{B})$ or $500 \mu \mathrm{g}(\mathbf{C}, \mathbf{D}) \mathrm{NPs} . \mathrm{n}=6$. Abbreviations are the same as in Figure 1. Box plots show median and interquartile range $\left(25^{\text {th }}\right.$ and $75^{\text {th }}$ percentiles). 

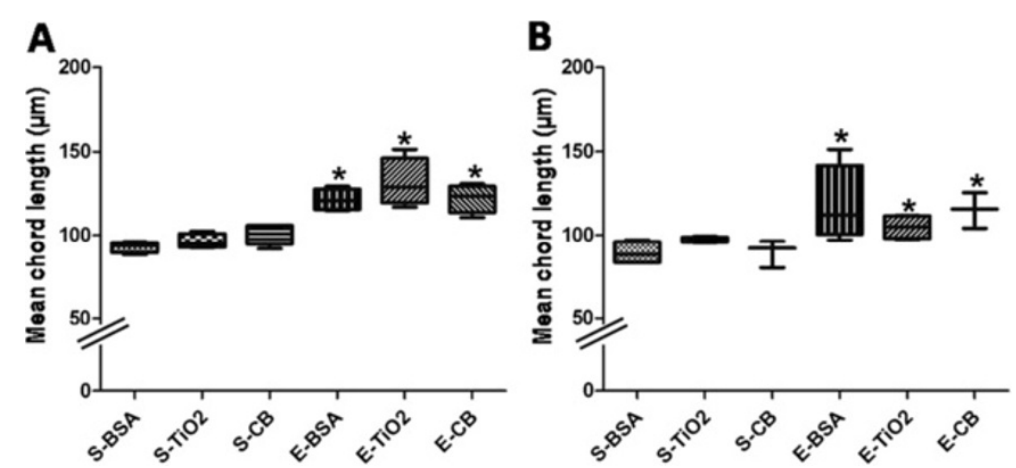

Figure 3 Emphysema quantification. Emphysema quantification assessed by measurement of the alveolar mean chord length at D21, in presence of $100 \mu \mathrm{g}(\mathbf{A})$ or $500 \mu \mathrm{g}$ (B) NPs. *: $p<0.05$ vs S-BSA. $\mathrm{n}=4$. Abbreviations are the same as in Figure 1. Box plots show median and interquartile range $\left(25^{\text {th }}\right.$ and $75^{\text {th }}$ percentiles).

were located in the alveolar lumen and in the perivascular and peribronchial infiltrates (Figure 6A). Additionally, NPs aggregates were observed in some CD68 positive cells.

\section{Discussion}

The main results of our study are that: 1) $\mathrm{TiO}_{2} \mathrm{NPs}$ did not induce inflammation per se and did not aggravate elastase-induced pulmonary inflammation and emphysema, except for an increase in elastase-induced MMP12 mRNA expression in the lung, and 2) CB NPs induced perivascular/peribronchial infiltration, increased HO-1 mRNA expression in the lung and increased MMP-12 mRNA and protein expression in alveolar macrophages without inducing emphysema. CB NPs aggravated elastase-induced perivascular/peribronchial inflammation but not emphysema. These results demonstrate that $\mathrm{TiO}_{2}$ or CB NPs did not induce and did not aggravate elastase-induced emphysema. However, CB NPs induced a lung inflammatory and protease response close to that induced by elastase and, notably, macrophage MMP-12 expression.

\section{Methodological considerations}

We decided to focus this study on the evaluation of NPs at doses that were relevant in terms of human exposure. We reasoned in terms of the current time-weighted average concentrations (TWA) recommendations for workers exposed to $\mathrm{TiO}_{2}$ (http://www.cdc.gov/niosh/ review/public/tio2/pdfs/TIO2Draft.pdf). These values are between 1.5 and $15 \mathrm{mg} / \mathrm{m}^{3}$ for a single shift of work (Table 1 of the above referenced document). In the present study, we used 0.4 and $2 \mathrm{mg} / \mathrm{kg}$ of $\mathrm{TiO}_{2} \mathrm{NPs}$, corresponding to a total administered-mass of 100 and $500 \mu \mathrm{g}$ per rat, for a $250 \mathrm{~g}$ rat. For a $70 \mathrm{~kg}$ human, this concentration would lead to the total administration of 28 and $140 \mathrm{mg}$. For a worker inhaling $10 \mathrm{~m}^{3}$ per workday, it implies $\mathrm{TiO}_{2}$ concentrations exposure of 2.8 and
$14 \mathrm{mg} / \mathrm{m}^{3}$, which are in the 2 extremes of the range of TWA values. Of course, we are aware that only a fraction of this inhaled dust reaches and remains in the lung. However, it is known that $\mathrm{TiO}_{2}$ particles have a long retention half-time (between 170 and 500 days for the fine and ultra-fine $\mathrm{TiO}_{2}$ particles respectively [31]). Therefore, the calculation of the total administered dose must take into account the duration between the day of NP administration and the day the animals are sacrificed. In our study, we observed a 14 days period between administration and sacrifice. Therefore, the dose initially administrated should be divided by 14 , which leads to values well below TWA values.

A potential criticism of this study is the respiratory delivery of NPs by a single intratracheal instillation instead of aerosol exposure. We acknowledge that aerosol exposure better reflects human exposure than intratracheal instillation. However, intratracheal instillation is a validated method of respiratory NPs delivery (see for example $[32,33])$. Moreover, given the long retention half time of NPs [31], a single instillation is well adapted to reproduce continuous exposure during short-term experimental periods like in the present study. It has to be noted that we used BSA to disperse the NPs in solution and this procedure could influence the biological effects of the NPs, as demonstrated by Val and colleagues in bronchial epithelial cells exposed to $\mathrm{CB}$ and $\mathrm{TiO}_{2}$ NPs [17]. However, other investigators did not find such interference with investigation of different types of carbon nanotubes [23]. This aspect should deserve further investigation.

Another potential criticism of this study is the utilization of the elastase-induced pulmonary emphysema model to analyze emphysema induced by cigarette smoke exposure, as occurs in humans. We decided not to use the cigarette smoke model because cigarette smoke contains NPs [34] that could prevent from examining the only effect of $\mathrm{CB}$ and $\mathrm{TiO}_{2}$ NPs on emphysema. We think 

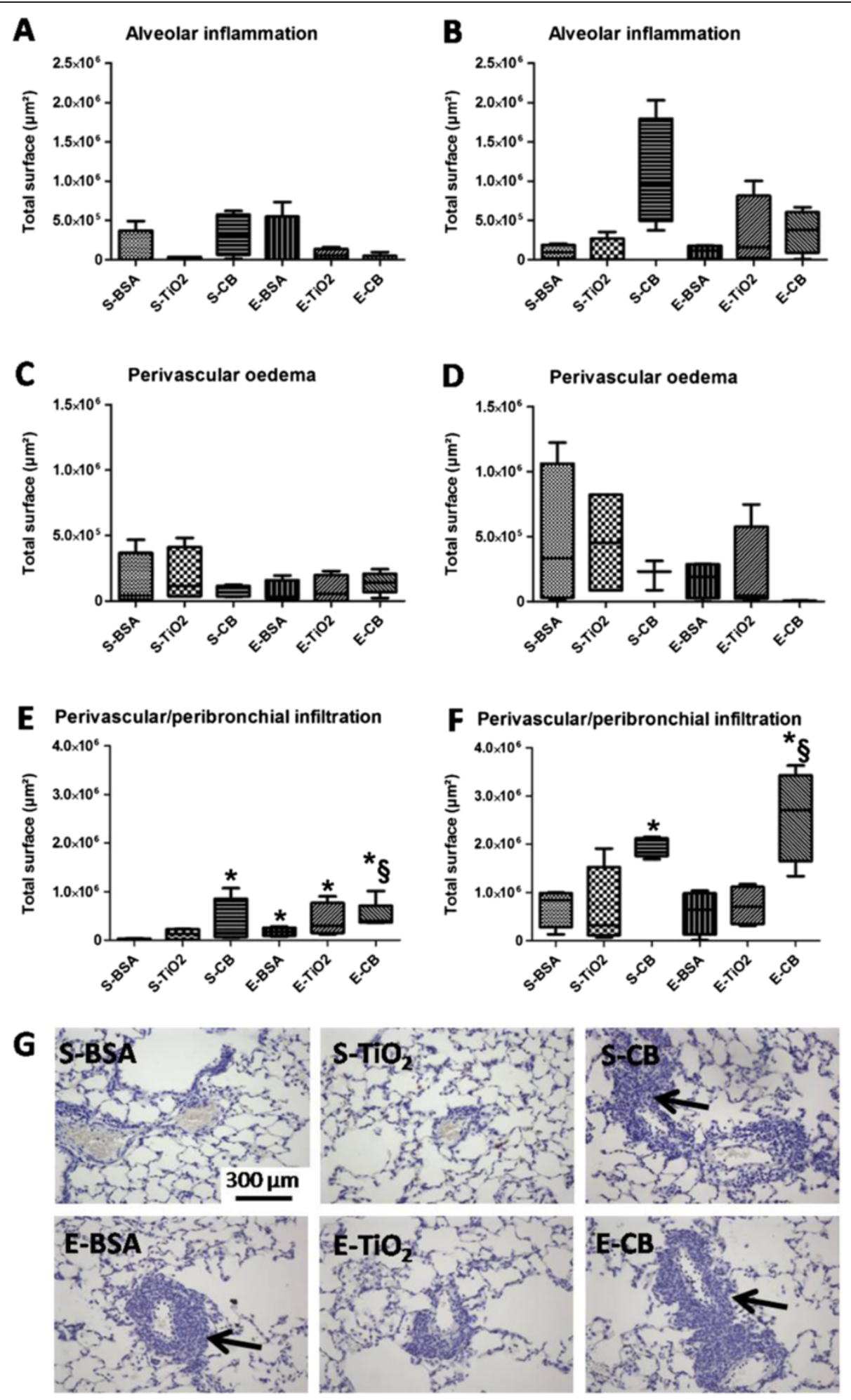

Figure 4 Quantitative analysis of histological inflammation in animals receiving $\mathbf{5 0 0} \boldsymbol{\mu g}$ NPs. Histological inflammation was quantified in terms of alveolar inflammation $(\mathbf{A}, \mathbf{B})$, perivascular oedema $(\mathbf{C}, \mathbf{D})$ and perivascular/peribronchial infiltration $(\mathbf{E}, \mathbf{F}) 8$ days $(\mathbf{A}, \mathbf{C}, \mathbf{E})$ or 21 days (B, D, F) after initial elastase administration in animals receiving $500 \mu \mathrm{g} \mathrm{NPs}$. Data are expressed as the total surface of the histological slide presenting the histological feature. ${ }^{*}: p<0.05$ vs S-BSA. $\S: p<0.05$ vs E-BSA. $\mathrm{n}=4$. Abbreviations are the same as in Figure 1. Box plots show median and interquartile range ( $25^{\text {th }}$ and $75^{\text {th }}$ percentiles). Panel G: representative histological staining of perivascular/peribronchial infiltrates in rat lung at D21 in animals exposed to $500 \mu \mathrm{g}$ NPs. Arrows point to perivascular infiltrates. Magnification x20. 

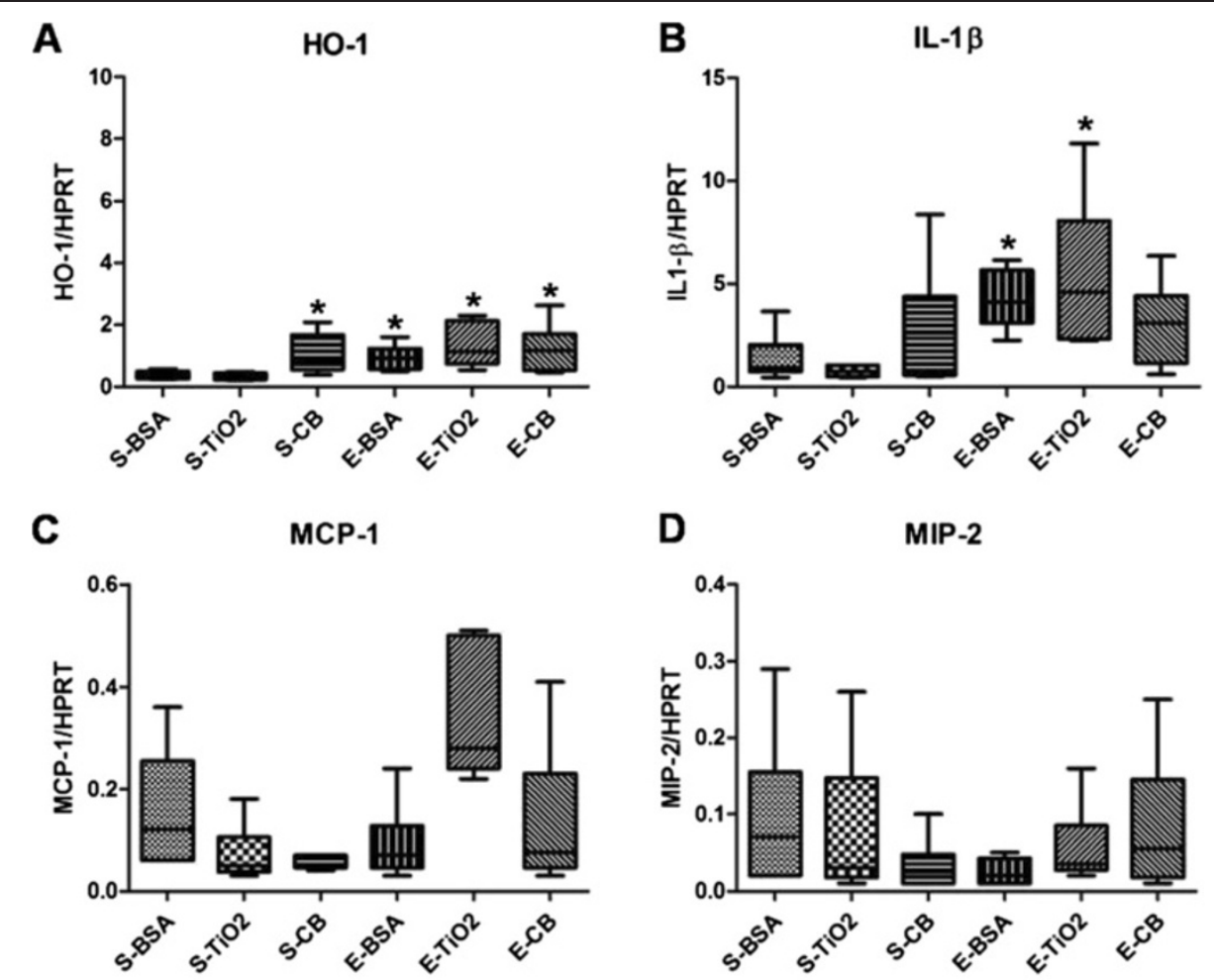

D MIP-2
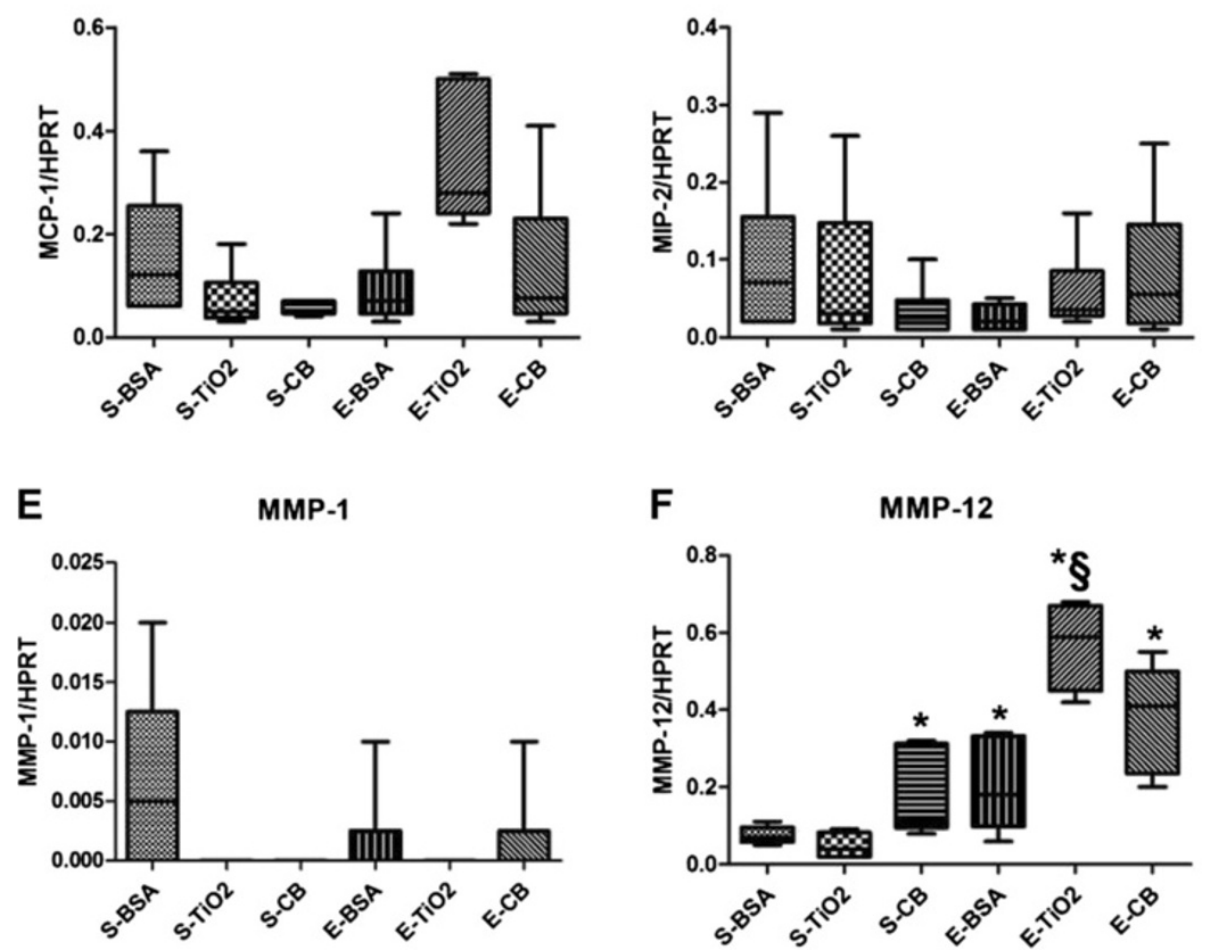

Figure 5 Gene expression at D21 in animals receiving $\mathbf{5 0 0} \boldsymbol{\mu g}$ NPs. Quantification of mRNA expression of the different genes at D21 by RT-qPCR. Data are expressed as the ratio to HPRT as housekeeping gene. Rats were exposed to $500 \mu \mathrm{g} \mathrm{NPs.}{ }^{*}: p<0.05$ vs S-BSA. $\S: p<0.05$ vs E-BSA. $n=6$. Abbreviations are the same as in Table 1 . Box plots show median and interquartile range $\left(25^{\text {th }}\right.$ and $75^{\text {th }}$ percentiles).

that the elastase model was appropriate for the present study for the following reasons. First, animals receiving a bolus of exogenous elastase into the lung exhibit lung damage consistent with emphysema, which is progressive [21], and involves many of the main pathophysiologic changes observed in cigarette smoke-induced emphysema in humans and animals, i.e. inflammation, oxidative stress [35], alveolar cell apoptosis [20] [21], and MMP-12 induction [21]. Second, elastase-induced emphysema can be modulated by different conditions (i.e. IL-6 or Nrf2 knocking down $[21,35]$ ), showing that it's a dynamic process, susceptible to be modulated by exposure to NPs, which does not result only from initial tissue destruction by exogenous elastase. Moreover, we took care of using a dose of elastase inducing a degree of emphysema similar to that observed after cigarette smoke exposure (near 30\% increase in mean linear intercept [36]). Finally, the expression of major actors of cigarette smoke-induced emphysema, such as HO-1, MMP-12 and IL-1 $\beta$ was increased in our elastase-instilled animals, supporting the relevance of the model.

Emphysema was quantified by the measurement of the mean chord length, which is a standard stereological method to quantify alveolar surface area $[27,28,37,38]$. However, care must be taken when using this method because it can be fraught with a number of pitfalls 


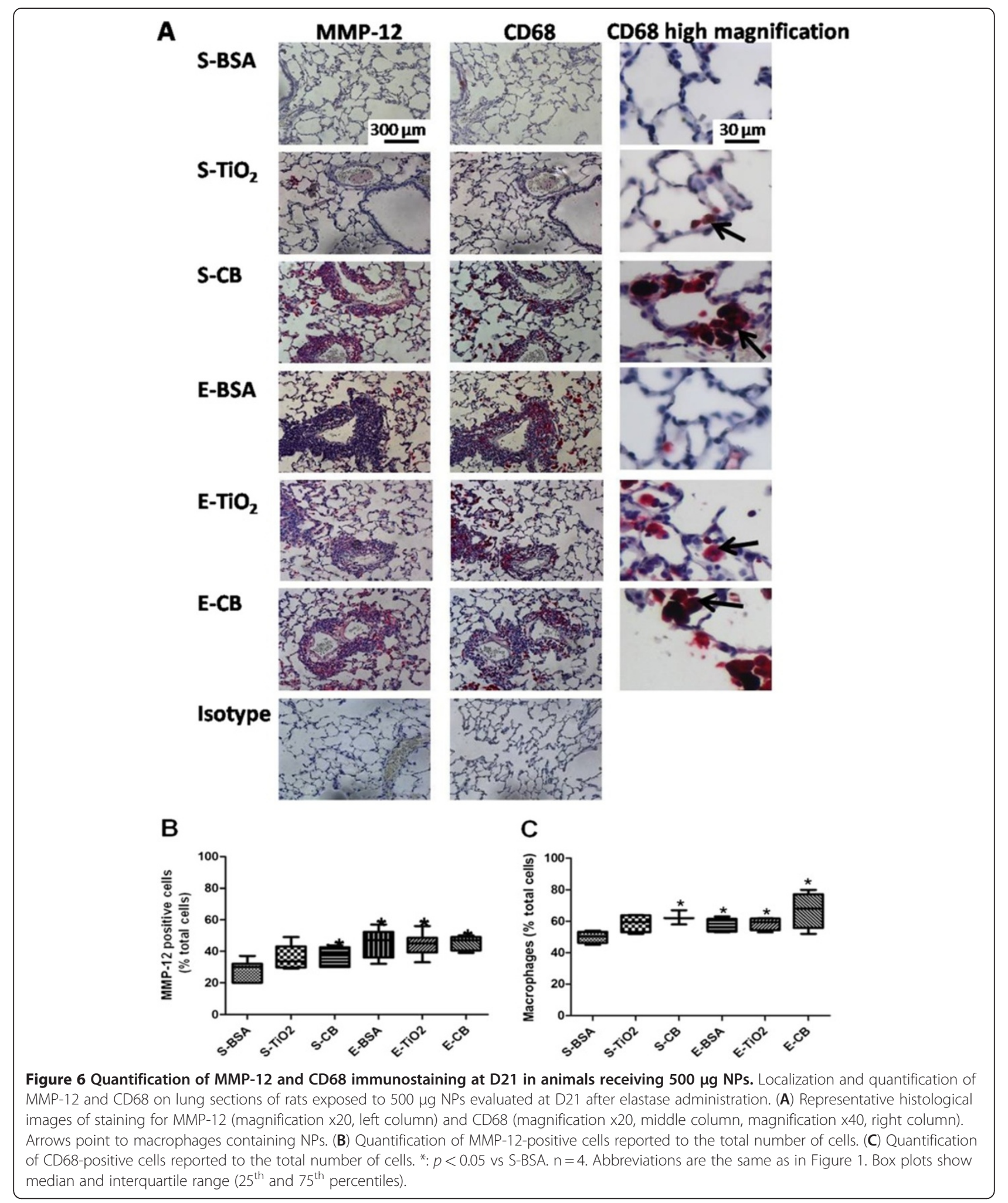

$[27,28]$. First, intercept lengths measured on microscopic slides are primarily determined by the inflation level at which the specimen has been held during tissue preparation. Therefore, in order to ensure the accurate comparison of the different groups, particular attention was paid to fix the lungs at a similar transpleural pressure $\left(25 \mathrm{cmH}_{2} \mathrm{O}\right.$ for $3 \mathrm{~h}$ ) before holding them in $4 \%$ paraformaldehyde. Second, we ensured that sampling of 
intercepts avoid edge effects that cause underrepresentation of very long intercepts as they occur, when the test line lies in the direction of alveolar ducts. Finally, care was taken to avoid any particle contained in the air space image (a speck of dust for example) that may intersect the scan line and thus cut an intercept in half so that two short chords are recorded instead of one longer one. This point is particularly important in animals exposed to NPs, since one can consider that isolated NPs in alveolar lumen could behave like a speck of dust, leading thus to underestimation of emphysema in these animals. However, no isolated NPs were observed, and thus this possibility can be ruled out.

\section{Results discussion}

We compared NPs that had similar sizes, but different specific surface areas, since specific surface area was 3 times greater for CB than for $\mathrm{TiO}_{2}$ NPs. In vivo and in vitro studies demonstrated that the surface area of NPs could be a main determinant of their proinflammatory effects $[16,39-42]$. This parameter and/or a different surface reactivity, related to the chemical nature of the NPs, could explain the difference in their inflammatory effects in the present study. It has been demonstrated that $\mathrm{TiO}_{2}$ and CB NPs elicited distinct apoptotic pathways [43], which could also impact their effects on the animals. However, no morphological sign of apoptosis was observed in the rat lungs. In contrast to $\mathrm{TiO}_{2}$ NPs, CB NPs induced inflammation and expression of the oxidative stress marker HO-1 and the protease MMP-12. Using the same NPs as we used, Hussain and coworkers [44] showed that the reactivity of CB NPs was higher than that of $\mathrm{TiO}_{2} \mathrm{NPs}$, as evaluated by the production of reactive oxygen species in acellular conditions. The increase in $\mathrm{HO}-1$ expression that we observed supports an oxidative effect of CB NPs [45,46], which has been already described in bronchial epithelial cells [43], and could be responsible for the inflammatory effect of CB NPs [47]. Although we did not find an increase in inflammatory cells in BAL, we observed clear inflammatory histological alterations (perivascular and peribronchial infiltration of neutrophils, lymphocytes and macrophages), as observed previously with other particles [44,48]. Macrophages engulfed CB NPs, apparent as pigmentation in the histological sections. In addition to attracting macrophages to the lung, CB NPs activated these cells, as revealed by their increased MMP- 12 protein expression detected by immunohistochemistry. We and others $[48,49]$ showed that different particles, such Paris Metro or atmospheric particulate matter (PM 10), could induce MMP-12 expression in macrophages. The present results provide the first demonstration of an increase in MMP-12 expression by manufactured NPs, both at the mRNA and protein levels.
Although we analyzed MMP-12 protein expression and its localization, we did not measure its activity. However, our results showing MMP-12 protein expression in macrophages are compatible with the presence of an active enzyme. Indeed, Cobos-Correa and coworkers [49] demonstrated in mice intratracheally instilled with PM 10 particles that active MMP-12 is bound to the membrane of alveolar macrophages. The increase in MMP-12 expression after a single exposure CB NPs could have important pathophysiological consequences because this protease plays a critical role in emphysema and COPD [50,51]. Continuous exposure to relevant doses of CB NPs could be consistent with a continuous degradation of pulmonary elastin, which could lead to a progressive and chronic degradation of lung function, as observed in smokers developing COPD [51]. Oxidative stress, revealed by the increased $\mathrm{HO}-1$ expression, could explain MMP-12 induction after CB NPs administration [52].

$\mathrm{TiO}_{2}$ NPs did not induce inflammation or protease expression per se but, rather, potentiated MMP-12 mRNA induction by elastase. This result is in line with data from Hussain and coworkers [44] showing that $\mathrm{TiO}_{2} \mathrm{NPs}$, at a dose similar to ours, potentiated toluene diisocyanate-induced allergic inflammation in mice without inducing inflammation per se. However, the relevance of the potentiation of elastase-induced MMP-12 mRNA expression by $\mathrm{TiO}_{2}$ is questionable, because we were unable to detect a parallel increase in protein expression. Moreover, this phenomenon was observed in the absence of a parallel increase in $\mathrm{HO}-1$ and IL- $1 \beta$ expression, which suggests that the effect of $\mathrm{TiO}_{2} \mathrm{NPs}$ on MMP-12 expression is independent of oxidative stress or IL-1 $\beta$ induction. Further experiments are needed to better understand this phenomenon.

CB NPs were unable to potentiate elastase-induced emphysema, although they induced inflammation and MMP-12 expression per se and potentiated elastaseinduced perivascular/peribronchial infiltration. This result agrees with data reported by Inoue and coworkers [18] in the elastase-induced emphysema model showing that CB NPs with a specific surface area and a diameter similar to our NPs, and at a dose similar to that used in our study, also induced inflammation per se and potentiated elastase-induced inflammation but not emphysema. Inoue and coworkers [18] administered CB NPs simulatenously with elastase whereas we administered NPs 1 week after elastase to assess their effects on the development of already constituted but still progressing emphysema [21]. The similar absence of potentiation of emphysema in the 2 studies shows that the timing of $\mathrm{CB}$ NPs administration is not a major determinant of this phenomenon. One car argue that the relatively short period elapsed after CB NPs could be insufficient to 
allow emphysema potentiation. Although we cannot exclude this hypothesis, other interventions such as administration of macrophage-colony stimulating factor, in a similar time frame than in the present study, was able to aggravate elastase-induced emphysema [53]. Interestingly, the potentiation of elastase-induced inflammation by CB NPs is in contrast with a reduced inflammatory response to bacterial infection in elastase-instilled animals [54,55], suggesting a specific effect of NPs in this model.

\section{Conclusion}

This study demonstrates an absence of induction and aggravation of elastase-induced emphysema with the administration of relevant doses of $\mathrm{TiO}_{2}$ or CB NPs. This result shows that not all the exposures to different NPs are associated with adverse health effects. However, CB NPs per se aggravated elastase-induced histological inflammation and increased expression of MMP-12, a major protease involved in elastin breakdown. Further studies will be needed to examine the implications of these findings.

\section{Abbreviations \\ BAL: Bronchoalveolar lavage; BET: Brunauer Emmett Teller; BSA: Bovine serum albumin; CB: Carbon black; COPD: Chronic obstructive pulmonary disease; HO-1: Heme oxygenase-1; HPRT: Hypoxanthine phosphoribosyltransferase; IL-1 $\beta$ : Interleukin 1 $\beta$; IQR: Interquartile range; LAL: Limulus Amebocyte Lysate; MCP-1: Monocyte chemotactic protein 1; MIP-2: Macrophage inflammatory protein 2; MMP: Matrix metalloproteinase; NPs: Nanoparticles; PSD: Particle Size Distribution function; RT-qPCR: Real-Time quantitative PCR; \\ $\mathrm{TiO}_{2}$ : Titanium dioxide; TEM: Transmission electronic microscopy.}

\section{Competing interests}

The authors declare that they have no competing interests.

\section{Authors' contribution}

$S L, G L$ and JB designed the study. LA, EB and ASD characterized the NP. AR, $F R$ and GL conducted the animal's instillations experiments. AR, LA and MD performed the biological assays. JTVN helped with the histological analysis of inflammation. LA, and JB drafted the manuscript, and JCP and SL helped with the final version. All authors read and approved the final manuscript.

\section{Acknowledgements}

The authors thank Nathalie Herlin and Aurélie Habert from the Atomic Energy Commission (Laboratoire Francis Perrin) for their support in NPs characterization, Olivier Thibaudeau (Hôpital Xavier Bichat, Paris) and Jocelyne Fleury (Hôpital Thenon, Paris) for their collaboration and Philippe Caramelle and Marie-Laure Franco (Inserm U955, Team 4) for technical help during the in vivo studies.

This work was supported by the "Agence Nationale de la Recherche France" (Nanotox project, 059 79-05 SET 024-01), the "Société de Pneumologie de Langue Française" for a master's grant for Agnès Roulet, the "ABIES" PhD program for a PhD grant for Lucie Armand, and the "Agence nationale de sécurité sanitaire de l'Alimentation, de l'Environnement et du Travail" (ANSES) for a PhD grant and funding for Esther Belade.

\section{Author details}

${ }^{1}$ Inserm U955, Equipe 4, Créteil 94000, France. ${ }^{2}$ Université Paris Est, Faculté de Médecine, Créteil 94000, France. ${ }^{3}$ Institut National de l'Environnement Industriel et des Risques (INERIS), Verneuil en Halatte, France. ${ }^{4}$ AP-HP, Hôpital Henri Mondor, Département de pathologie, Créteil 94010, France. ${ }^{5}$ Centre Hospitalier Intercommunal, Service de pneumologie et pathologie professionnelle, Créteil 94000, France. ${ }^{6}$ AP-HP, Hôpital Henri Mondor, Service de Physiologie Explorations Fonctionnelles, Créteil 94000, France.

Received: 16 February 2012 Accepted: 26 July 2012

Published: 31 July 2012

\section{References}

1. Yoshida T, Tuder RM: Pathobiology of cigarette smoke-induced chronic obstructive pulmonary disease. Physiol Rev 2007, 87(3):1047-1082.

2. Mathers $C D$, Loncar D: Projections of global mortality and burden of disease from 2002 to 2030. PLoS Med 2006, 3(11):e442.

3. Abboud RT, Vimalanathan S: Pathogenesis of COPD. Part I. The role of protease-antiprotease imbalance in emphysema. Int J Tuberc Lung Dis 2008, 12(4):361-367.

4. Nel A, Xia T, Madler L, Li N: Toxic potential of materials at the nanolevel. Science 2006, 311(5761):622-627.

5. Boczkowski J, Hoet P: What's new in nanotoxicology? Implications for public health from a brief review of the 2008 literature. Nanotoxicology 2011, 4(1):1-14.

6. Baan RA: Carcinogenic hazards from inhaled carbon black, titanium dioxide, and talc not containing asbestos or asbestiform fibers: recent evaluations by an IARC Monographs Working Group. Inhal Toxicol 2007, 19(Suppl 1):213-228.

7. Johnston HJ, Hutchison GR, Christensen FM, Peters S, Hankin S, Aschberger K, Stone V: A critical review of the biological mechanisms underlying the in vivo and in vitro toxicity of carbon nanotubes: The contribution of physico-chemical characteristics. Nanotoxicology 2010, 4:207-246.

8. Warheit DB, Webb TR, Reed KL, Frerichs S, Sayes CM: Pulmonary toxicity study in rats with three forms of ultrafine-TiO2 particles: differential responses related to surface properties. Toxicology 2007, 230(1):90-104

9. Yazdi AS, Guarda G, Riteau N, Drexler SK, Tardivel A, Couillin I, Tschopp J: Nanoparticles activate the NLR pyrin domain containing 3 (NIrp3) inflammasome and cause pulmonary inflammation through release of IL-1alpha and IL-1beta. Proc Natl Acad Sci U S A 2010, 107(45):19449-19454.

10. Churg A, Stevens B, Wright $\mathrm{J}$ : Comparison of the uptake of fine and ultrafine TiO2 in a tracheal explant system. Am J Physiol 1998, 274(1 Pt 1):L81-86.

11. Chen HW, Su SF, Chien CT, Lin WH, Yu SL, Chou CC, Chen JJ, Yang PC: Titanium dioxide nanoparticles induce emphysema-like lung injury in mice. Faseb J 2006, 20(13):2393-2395.

12. Hext PM: Current perspectives on particulate induced pulmonary tumours. Hum Exp Toxicol 1994, 13(10):700-715.

13. Bachoual R, Boczkowski J, Goven D, Amara N, Tabet L, On D, Lecon-Malas V, Aubier M, Lanone S: Biological effects of particles from the paris subway system. Chem Res Toxicol 2007, 20(10):1426-1433.

14. Fujita K, Horie M, Kato H, Endoh S, Suzuki M, Nakamura A, Miyauchi A, Yamamoto K, Kinugasa S, Nishio K, et al: Effects of ultrafine TiO2 particles on gene expression profile in human keratinocytes without illumination: involvement of extracellular matrix and cell adhesion. Toxicol Lett 2009, 191(2-3):109-117.

15. Raymond L, Eck S, Mollmark J, Hays E, Tomek I, Kantor S, Elliott S, Vincenti $\mathrm{M}$ : Interleukin-1 beta induction of matrix metalloproteinase-1 transcription in chondrocytes requires ERK-dependent activation of CCAAT enhancer-binding protein-beta. J Cell Physiol 2006, 207(3):683-688.

16. Hussain S, Thomassen LC, Ferecatu I, Borot MC, Andreau K, Martens JA, Fleury J, Baeza-Squiban A, Marano F, Boland S: Carbon black and titanium dioxide nanoparticles elicit distinct apoptotic pathways in bronchial epithelial cells. Part Fibre Toxicol 2010, 7:10.

17. Val S, Hussain S, Boland S, Hamel R, Baeza-Squiban A, Marano F: Carbon black and titanium dioxide nanoparticles induce pro-inflammatory responses in bronchial epithelial cells: need for multiparametric evaluation due to adsorption artifacts. Inhal Toxicol 2009, 21(Suppl 1):115-122.

18. Inoue K, Yanagisawa $R$, Koike E, Nakamura R, Ichinose T, Tasaka S, Kiyono M, Takano H: Effects of carbon black nanoparticles on elastase-induced emphysematous lung injury in mice. Basic Clin Pharmacol Toxicol 2011, 108(4):234-240.

19. Mercer RR, Crapo JD: Structural changes in elastic fibers after pancreatic elastase administration in hamsters. J App/ Physiol 1992, 72(4):1473-1479. 
20. Sawada M, Ohno Y, La BL, Funaguchi N, Asai T, Yuhgetsu H, Takemura G, Minatoguchi S, Fujiwara H, Fujiwara T: The Fas/Fas-ligand pathway does not mediate the apoptosis in elastase-induced emphysema in mice. Exp Lung Res 2007, 33(6):277-288.

21. Tasaka S, Inoue K, Miyamoto K, Nakano Y, Kamata H, Shinoda H, Hasegawa N, Miyasho T, Satoh M, Takano H, et al: Role of interleukin-6 in elastase-induced lung inflammatory changes in mice. Exp Lung Res 2010, 36(6):362-372.

22. Fubini B, Ghiazza M, Fenoglio I: Physico-chemical features of engineered nanoparticles relevant to their toxicity. Nanotoxicology 2010, 4:347-363.

23. Elgrabli D, Abella-Gallart S, Aguerre-Chariol O, Robidel F, Rogerieux F, Boczkowski J, Lacroix G: Effect of BSA on carbon nanotube dispersion for in vivo and in vitro studies. Nanotoxicology 2007, 1:266-278.

24. Boyer L, Plantier L, Dagouassat M, Lanone S, Goven D, Caramelle P, Berrehar F, Kerbrat S, Dinh-Xuan AT, Crestani B, et al: Role of nitric oxide synthases in elastase-induced emphysema. Lab Invest 2011, 91(3):353-362.

25. Elekes K, Helyes Z, Kereskai L, Sandor K, Pinter E, Pozsgai G, Tekus V, Banvolgyi A, Nemeth J, Szuts T, et al: Inhibitory effects of synthetic somatostatin receptor subtype 4 agonists on acute and chronic airway inflammation and hyperreactivity in the mouse. Eur J Pharmacol 2008, 578(2-3):313-322

26. Plantier L, Marchand-Adam S, Antico VG, Boyer L, De Coster C, Marchal J, Bachoual R, Mailleux A, Boczkowski J, Crestani B: Keratinocyte growth factor protects against elastase-induced pulmonary emphysema in mice. Am J Physiol Lung Cell Mol Physiol 2007, 293(5):L1230-1239.

27. Knudsen L, Weibel ER, Gundersen HJ, Weinstein FV, Ochs M: Assessment of air space size characteristics by intercept (chord) measurement: an accurate and efficient stereological approach. J App/ Physiol 2010, 108(2):412-421.

28. Hsia CC, Hyde DM, Ochs M, Weibel ER: How to measure lung structurewhat for? On the "Standards for the quantitative assessment of lung structure". Respir Physiol Neurobiol 2010, 171(2):72-74.

29. Abramoff M, Magelhaes P, Ram S: Image Processing with ImageJ. Biophotonics International 2004, 11:36-42.

30. Mehnert W, Mader K: Solid lipid nanoparticles: production, characterization and applications. Adv Drug Deliv Rev 2001 47(2-3):165-196

31. Oberdorster G, Ferin J, Lehnert BE: Correlation between particle size, in vivo particle persistence, and lung injury. Environ Health Perspect 1994, 102(Suppl 5):173-179.

32. Yokohira M, Kuno T, Yamakawa K, Hosokawa K, Matsuda Y, Hashimoto N Suzuki S, Saoo K, Imaida K: Lung toxicity of 16 fine particles on intratracheal instillation in a bioassay model using $\mathrm{f} 344$ male rats. Toxicol Pathol 2008, 36(4):620-631.

33. Sager TM, Castranova V: Surface area of particle administered versus mass in determining the pulmonary toxicity of ultrafine and fine carbon black: comparison to ultrafine titanium dioxide. Part Fibre Toxicol 2009, 6:15.

34. van Dijk WD, Gopal S, Scheepers PT: Nanoparticles in cigarette smoke; real-time undiluted measurements by a scanning mobility particle sizer. Anal Bioanal Chem 2011, 399(10):3573-3578.

35. Ishii $Y$, Itoh $K$, Morishima $Y$, Kimura T, Kiwamoto T, lizuka T, Hegab AE, Hosoya T, Nomura A, Sakamoto T, et al: Transcription factor Nrf2 plays a pivotal role in protection against elastase-induced pulmonary inflammation and emphysema. J Immunol 2005, 175(10):6968-6975.

36. Wright $J$, Cosio M, Churg A: Animal models of chronic obstructive pulmonary disease. Am J Physiol Lung Cell Mol Physiol 2008, 295(1):L1-15.

37. Houghton AM, Quintero PA, Perkins DL, Kobayashi DK, Kelley DG, Marconcini LA, Mecham RP, Senior RM, Shapiro SD: Elastin fragments drive disease progression in a murine model of emphysema. J Clin Invest 2006, 116(3):753-759.

38. Maeno T, Houghton AM, Quintero PA, Grumelli S, Owen CA, Shapiro SD: CD8+ T Cells are required for inflammation and destruction in cigarette smoke-induced emphysema in mice. J Immunol 2007, 178(12):8090-8096.

39. Monteiller C, Tran L, MacNee W, Faux S, Jones A, Miller B, Donaldson K: The pro-inflammatory effects of low-toxicity low-solubility particles, nanoparticles and fine particles, on epithelial cells in vitro: the role of surface area. Occup Environ Med 2007, 64(9):609-615.

40. Oberdorster G, Oberdorster E, Oberdorster J: Nanotoxicology: an emerging discipline evolving from studies of ultrafine particles. Environ Health Perspect 2005, 113(7):823-839.
41. Singh S, Shi T, Duffin R, Albrecht C, van Berlo D, Hohr D, Fubini B, Martra G, Fenoglio I, Borm PJ, et al: Endocytosis, oxidative stress and IL-8 expression in human lung epithelial cells upon treatment with fine and ultrafine TiO2: role of the specific surface area and of surface methylation of the particles. Toxicol Appl Pharmacol 2007, 222(2):141-151.

42. Stoeger T, Reinhard C, Takenaka S, Schroeppel A, Karg E, Ritter B, Heyder J, Schulz $\mathrm{H}$ : Instillation of six different ultrafine carbon particles indicates a surface area threshold dose for acute lung inflammation in mice. Environ Health Perspect 2006, 114(3):328-333.

43. Hussain S, Boland S, Baeza-Squiban A, Hamel R, Thomassen LC, Martens JA, Billon-Galland MA, Fleury-Feith J, Moisan F, Pairon JC, et al: Oxidative stress and proinflammatory effects of carbon black and titanium dioxide nanoparticles: role of particle surface area and internalized amount. Toxicology 2009, 260(1-3):142-149.

44. Hussain S, Vanoirbeek JA, Luyts K, De Vooght V, Verbeken E, Thomassen LC, Martens JA, Dinsdale D, Boland S, Marano F, et al: Lung exposure to nanoparticles modulates an asthmatic response in a mouse model. Eur Respir J 2011, 37(2):299-309.

45. Almolki A, Guenegou A, Golda S, Boyer L, Benallaoua M, Amara N, Bachoual R, Martin C, Rannou F, Lanone S, et al: Heme oxygenase-1 prevents airway mucus hypersecretion induced by cigarette smoke in rodents and humans. Am J Pathol 2008, 173(4):981-992.

46. Guenegou A, Leynaert B, Benessiano J, Pin I, Demoly P, Neukirch F, Boczkowski J, Aubier M: Association of lung function decline with the heme oxygenase-1 gene promoter microsatellite polymorphism in a general population sample. Results from the European Community Respiratory Health Survey (ECRHS), France. J Med Genet 2006, 43(8):e43.

47. Li JJ, Muralikrishnan S, Ng CT, Yung LY, Bay BH: Nanoparticle-induced pulmonary toxicity. Exp Biol Med (Maywood) 2010, 235(9):1025-1033.

48. Kobayashi N, Naya M, Endoh S, Maru J, Yamamoto K, Nakanishi J: Comparative pulmonary toxicity study of nano- $\mathrm{TiO}(2)$ particles of different sizes and agglomerations in rats: different short- and long-term post-instillation results. Toxicology 2009, 264(1-2):110-118.

49. Cobos-Correa A, Trojanek JB, Diemer S, Mall MA, Schultz C: Membranebound FRET probe visualizes MMP12 activity in pulmonary inflammation. Nat Chem Biol 2009, 5(9):628-630.

50. Hautamaki RD, Kobayashi DK, Senior RM, Shapiro SD: Requirement for macrophage elastase for cigarette smoke-induced emphysema in mice. Science 1997, 277(5334):2002-2004.

51. Hunninghake GM, Cho MH, Tesfaigzi Y, Soto-Quiros ME, Avila L, Lasky-Su J, Stidley C, Melen E, Soderhall C, Hallberg J, et al: MMP12, lung function, and COPD in high-risk populations. N Engl J Med 2009, 361(27):2599-2608.

52. Lavigne MC, Eppihimer MJ: Cigarette smoke condensate induces MMP-12 gene expression in airway-like epithelia. Biochem Biophys Res Commun 2005, 330(1):194-203.

53. Ishikawa T, Aoshiba K, Yokohori N, Nagai A: Macrophage colonystimulating factor aggravates rather than regenerates emphysematous lungs in mice. Respiration 2006, 73(4):538-545.

54. Inoue S, Nakamura H, Otake K, Saito H, Terashita K, Sato J, Takeda H, Tomoike H: Impaired pulmonary inflammatory responses are a prominent feature of streptococcal pneumonia in mice with experimental emphysema. Am J Respir Crit Care Med 2003, 167(5):764-770.

55. Pang B, Hong W, West-Barnette SL, Kock ND, Swords WE: Diminished ICAM-1 expression and impaired pulmonary clearance of nontypeable Haemophilus influenzae in a mouse model of chronic obstructive pulmonary disease/emphysema. Infect Immun 2008, 76(11):4959-4967.

doi:10.1186/1471-2466-12-38

Cite this article as: Roulet et al:: Intratracheally administered titanium dioxide or carbon black nanoparticles do not aggravate elastaseinduced pulmonary emphysema in rats. BMC Pulmonary Medicine 2012 12:38. 